\title{
[opinião]
}

$\mathrm{O}$ que pesquisar

no design

da informação

para chegar

ao século XXII?* 


\section{PESQUISAR PARA QUÊ?}

Ao ser proposto pela diretoria da SBDI o tema Perspectivas da Pesquisa em Design diante da Crise Mundial de Saúde, a primeira coisa que me passou à cabeça foi: PESQUISAR, PARA QUÊ? Obviamente, não no sentido de PARA QUE SERVE ISSO? Mas sim no sentido de O QUE EU QUERO COM ISSO? Qual sentido a pesquisa em Design deve ter? Para deixar de imediato meu posicionamento geral: eu quero contribuir para superar o Capitalismo.

A primeira vez que ouvi a pergunta POR QUE PESQUISAR EM DESIGN?, foi elaborada de forma pragmática por Gui Bonsiepe, em um encontro promovido pelo Laboratório de Programação Visual | LABPV da UFPE em 1992, ou 1993. Na época, Bonsiepe alertava que sem pesquisa, sem a produção de novos

* Este ensaio revisa e expande intervenção conhecimentos, a profissão de designer

realizada no Webinar Perspectivas da Pesquisa em Design diante da Crise Mundial de Saúde, promovido pela Sociedade Brasileira do Design da Informação SBDI em 29/07/2020. 
corria o risco de desaparecer, pois parte do saber já estava sendo incorporado nos softwares gráficos de então. Hoje percebo de forma clara que não apenas os conhecimentos e os saberes estavam sendo incorporados, mas as ações que perfaziam a atividade estavam, aos poucos, sendo modificadas e incorporadas pelos artefatos da profissão. Há já algumas décadas que muitas atividades humanas vêm sendo aceleradamente incorporadas nos artefatos, praticamente todos hoje com algum componente digital. Nada contra, a priori, até porque novas atividades surgiram nessa conta, mas é preciso perceber as consequências.

Uma das mais nefastas é o esgotamento dos recursos naturais. Se mais e mais atividades humanas são incorporadas nos artefatos que criamos, tornando mais fácil e rápida a execução de tantas atividades, mais produtos e resultados dessas atividades são gerados. Poderia ser diferente, por exemplo, se o sistema capitalista aceitasse que esse aumento da produtividade se tornasse tempo livre. Seria a concretização da promessa da tecnologia: nos livrar do trabalho.

Costumo contar uma lembrança de meu pai como metáfora da situação. Nos anos 1970, costumava vê-lo trabalhando à noite na grande mesa da sala de jantar em nossa casa. Cercado de livros, tábuas de logaritmos, papéis, caneta e uma régua de cálculo, passava 
dias fazendo cálculos de engenheiro. A régua de cálculo, seu computador pessoal. Quem já viu uma régua de cálculo sabe o trabalho duro que era resolver as equações com esse instrumento. Eu brinco, sugerindo que ele estivesse calculando uma ponte, sabendo que provavelmente era avaliação termodinâmica de alguma fábrica. Faço isso porque torna o produto de seu trabalho mais concreto, menos abstrato, ao mesmo tempo, mais poético. Também sugiro que $o$ trabalho durasse 15 dias, apesar de que para a metáfora o tempo exato seja irrelevante. Depois, já na segunda metade dos anos 70 , surgiram as calculadoras científicas, com senos, cossenos, um muito pouco de memória etc. A rotina mudou para a execução dos cálculos, ao invés de deslizar a guia e escalas de sua régua para lá, depois para cá, passou a apertar seguidamente os botões da sua Hewlett-Packard enquanto conferia o manual. Os cálculos começaram a ser feitos mais rapidamente. Hoje, meu pai, se ainda fora calculador de pontes, usaria, na pior das hipóteses, uma planilha de cálculo e bastaria entrar com os dados para colher os resultados. 0 que fazia em 15 dias, faria em poucas horas. Porém, ao contrário de ganhar 14 dias de folga, teria provavelmente que calcular umas 15 pontes para sustentar a vida de sua família de 5 filhos.

Da mesma forma, o que um designer fazia em $n$ dias na virada dos anos 90 , hoje pode ser feito em poucas horas. Mas já não corresponde proporcionalmente ao seu sustento de 30 anos atrás. Este é um processo em curso, que atinge a quase totalidade das 
profissões. Não é à toa a precarização do trabalho como fenômeno mundial. Atende à lógica do sistema. No limite, caminha-se para o cenário de ficção científica da Rede Skynet ${ }^{01} \mathrm{em}$ que a imensa parte da humanidade não é necessária. Este é um dos atuais legados do arranjo produtivo que nos configura a vida há alguns séculos.

Essa realidade imposta pela pandemia é também fruto deste arranjo. Nunca o Capital foi tão forte quanto no contemporâneo estágio financeiro em que estamos. Nunca a riqueza mundial esteve tão concentrada. Nunca a circulação de pessoas e mercadorias foi tão intensa e tão vasta. Nunca a biosfera esteve tão ameaçada. 0 salto interespécie que o Coronavírus realizou é fruto da forma como a vida da espécie humana está

01 A rede Skynet faz parte do universo de 0 exterminador do Futuro (The Terminator, 1984). 
organizada. E assim, voltamos a minha intenção: eu quero contribuir para superar o Capitalismo. Foi ele que nos trouxe até aqui. Para o Bem e para o Mal. Por isso não me refiro a ANIQUILAR, DERROTAR, ou DESTRUIR o Capitalismo, como poderiam desejar, mas sim SUPERAR. Porque é necessário distinguir as benesses e os males do sistema, a fim de buscar manter o que há de bom e superar o que há de ruim.

Esse é para mim o tema mais emergente. Como é que o Design, e mais especificamente, o Design da Informação, pode contribuir para a superação de um sistema produtivo injusto, socialmente perverso, que drena todos os recursos naturais, incluídos os biológicos, para o benefício insaciável de uma meia dúzia de indivíduos e seus círculos mais próximos? O que é possível fazer?

Porque a crise do Coronavírus demonstrou o potencial de uma crise sistêmica em escala planetária. E me faz pensar de forma imediata na crise climática que nos bate à porta. Demonstrou também que se pode realizar muita coisa, sem tantos deslocamentos. Nos trouxe forçadamente a uma diminuição, ao recolhimento. E me parece que é preciso repensar o futuro. E um futuro de MENOS restou possível. Menos objetos no mundo. Menos deslocamento humano. Menos produção. O que aparentemente aumentou foi a informação e seus meios. Minha opinião é que dentro da lógica deste sistema 
produtivo nunca teremos o controle neces-

sário sobre nosso destino enquanto espécie. Nas regras do jogo atual, o Capital nos guia para a maior crise sistêmica que viveremos. Os que trabalham, não temos voz e temos cada vez menos direitos. $O$ surpreendente é que o Capital é hoje um mero construto SOCIAL, um artefato simbólico sem lastro na realidade material. $O$ que é o dinheiro? Praticamente uma crença. Não menos efetiva por isso, pois o simbólico também é um instrumento capaz de muitas realizações.

Sendo assim, é hora de se perguntar de que forma podemos reconstruir um sistema produtivo mesquinho em sua essência, a fim de que possa servir ao humano, ao planeta Terra, à vida plena de seus integrantes.

Porque isso que nós temos hoje, é um bezerro de ouro, que de tanto adorado, possui poder verdadeiro sobre nós. O Capitalismo, entendido aqui em seu estágio financeiro, está drenando a vida na Terra. Como nós, artífices do não-natural, podemos atuar a fim de encontrar equilíbrio? O que precisamos fazer para que os paradigmas que guiam esse SISTEMA sejam quebrados e revistos? 


\section{O QUE FAZER}

A tarefa não é pequena. Nem fácil, como tantos já perceberam desde o século XIX. Mas esse é o tipo de problema que realmente vale a pena investigar. Um que não se tem a resposta. Um que exija a mobilização de muita inteligência e criatividade. Um que permita avançar e trazer benefícios a muitos. Esses são os melhores. Apesar de que, superar o Capitalismo possa parecer um problema distante do Design da Informação, creio que exista espaço para nos envolvermos na tarefa. Na verdade, acredito, existem muitas frentes possíveis.

Para termos algum sucesso entendo ser necessário estabelecer um programa de pesquisa que investigue como o construto se mantém. Quais mecanismos atuam e como é constituída a REPRESENTAÇão SOCIAL que o suporta. Porque boa parte do problema tem a ver com a mediação simbólica que nos impede de reconhecer as injustiças do sistema e seus mecanismos de expropriação. Os instrumentos simbólicos que permitem e justificam a manutenção de tantos à margem dos ganhos que o Capitalismo nos lega. Um programa que tenha foco em identificar, avaliar e reverter os paradigmas indesejáveis nos quais se funda o construto.

O meu principal argumento para a área é que, se há disputa simbólica, O DESIGN DA INFORMAção possui espaço para atuar. É questão apenas de tomar posição e agir. Uma das primeiras tarefas a contribuir para a superação do sistema, sair de seu estágio atual e alcançar outro de organização da vida de forma sustentável, é entender a verdadeira natureza do problema. Adotar uma perspectiva de dúvida 
sobre as principais verdades do construto e formular hipóteses. Como toda boa pesquisa. E nós temos muitos instrumentos para isso.

Uma tarefa óbvia é trazer outras áreas do conhecimento para perto, pois o problema é realmente complexo. A compreensão do problema será tão mais rica quanto forem diversificadas as visões. O que sugere um processo dinâmico que permita trocas variadas dos enfoques do problema ao longo do programa e que evolua de acordo com a sua compreensão e dos cenários futuros. A abordagem da APRENDIZAGEM EXPANSIVA de Engeström (2001) é um exemplo de uma tal metodologia evolutiva.

Outra tarefa possível é mapear os conceitos mais centrais que diferentes grupos sociais constroem em torno dos princípios do sistema capitalista. A Teoria da Representações Sociais da psicologia social é um campo que pode ajudar (MONTEIRO \& BARRETO CAMPELLO; 2013), ou mesmo a big data das redes e processos de data mining. 0 essencial é ter uma representação aproximada dos conceitos mais centrais que suportam socialmente a reprodução do sistema.

Alguns desses conceitos são do conhecimento comum. Como o DIREITO DE HERANÇA que apesar de contrário ao da MERITOCRACIA, não parece ser questionado. Como isso é possível? Que sistema de crenças e valores permite acomodar essa contradição? Alguns desses 
conceitos centrais são óbvios, como o de INDIVÍDUO ou CONCORRÊNCIA, outros terão que ser mapeados.

Outra tarefa importante, e já parcialmente em curso no Brasil, é a identificação e análise dos patrimônios material e imaterial que o Design da Informação ajudou a construir. Pesquisas do campo da Memória Gráfica (FARIAS \& BRAGA, 2018) são uma forma de resistência à perda de identidade e desterritorialização que o atual estágio do Capitalismo vem impondo. A compreensão de nosso atual estágio cultural como um processo histórico, no qual os produtos do Design se envolvem em significados e evoluem material e semanticamente, permite perceber outras formas de fazer, e consequentemente de ser.

Por fim, gostaria de sugerir uma mudança de paradigma projetual que abre caminhos para a pesquisa. Conforme sugerido 
anteriormente, os artefatos incorporam atividades em si. Este é um conceito que encontra fundamentação na Teoria da Atividade de Leontiev (1978). Na prática atual, o paradigma que guia esse fenômeno é fazer mais em menos tempo e com menos custo. Não necessariamente com menos recursos naturais como mostra as ilhas de plástico que se formam nos oceanos. Essa tem sido a força motriz do desenvolvimento do mundo artificial: produzir mais, consumir muito, usar menos tempo, remunerar pouco. Por extrapolação, é possível supor o esgotamento. A sugestão é inverter de alguma forma essa lógica. Nossos artefatos deveriam produzir menos, consumir pouco, usar mais tempo e remunerar bem. Uma elaboração de ideia simples, porém de difícil solução prática. Até porque, para ocorrer, se faz necessária uma mudança paradigmática interna, do próprio designer, pois os conceitos são artefatos simbólicos com os quais pensamos. Para projetar no sentido proposto, precisamos abandonar conceitos velhos e desenvolver novos. Apenas aqui, há um conjunto infinito de proposições cabíveis e investigações necessárias. Na minha opinião, os artefatos que desenvolvemos deveriam incorporar atividades que possuam a lógica do viver e não do ter, do solidário ao invés do egoísta, da distribuição no lugar da concentração. Só assim, acredito, chegaremos ao século XXII. 


\section{REFERÊNCIAS}

ENGESTRÖM, Y. Expansive Learning at Work:

Toward an activity theoretical reconceptualization, Journal of Education and Work, 14:1, 133-156, 2001.

FARIAS, Priscila Lena; BRAGA, Marcos da Costa. Dez ensaios sobre memória gráfica. [S.l: s.n.], 2018.

LEONT'EV, A. N. Activity, consciousness, and personality. Englewood Cliffs, New Jersey: Prentice-Hall, Inc., 1978.

MONTEIRO, M. C. M. ; BARRETO CAMPELLO, S. Teoria das Representações Sociais como ferramenta metodológica nos processos de Design. InfoDesign (SBDI. ONLINE), v. 10, p. 274-292, 2013. 